\title{
Acute Toxicity of Self Nano-emulsifying Formulation of Curcumin Analogue Gamavuton-0, A New Candidate for Rheumatoid Arthritis Treatment
}

\author{
L Chabib $^{1,2,3 *}$, Z Ikawati ${ }^{1}$, R Martien ${ }^{1}$, H Ismail ${ }^{1,4}$
}

\author{
${ }^{1}$ Faculty of Pharmacy, Gadjah Mada University, Yogyakarta, 555281, Indonesia \\ ${ }^{2}$ Pharmacy Department, Islamic University of Indonesia, Yogyakarta 55584, Indonesia \\ ${ }^{3}$ Professional Pharmacy Education Program, Islamic University of Indonesia, \\ Yogyakarta 55584, Indonesia \\ ${ }^{4}$ Curcumin Research Centre, Faculty of Pharmacy, UGM, Skip Utara Yogyakarta \\ 555281 , Indonesia
}

\begin{abstract}
Gamavuton-0 (GVT-0), a newly developed compound synthesized by a carbonyl group and a methylene reduction of Curcumin, has been proven to have several anti arthritic activities. The compound has been further proven to have no short-term toxicity in rat in vivo. However, GVT-0 still burdens low water solubility therefore poorly absorbed in oral administration. Currently, a self-nano-emulsifying system has been developed to formulate GVT-0 into a more effective oral anti RA candidate using various oils and surfactants (SNE GVT-0). To study whether this formulation would not alter the safety of the compound in oral administration, an in vivo acute toxicity testing was conducted. A 14 day-study was performed by using four groups of wistar strain Rattus norvegicus, three rats per group, with $300 \mathrm{mg} / \mathrm{kg}$ BW GVT-0 as preliminary dose and $2000 \mathrm{mg} / \mathrm{kg} \mathrm{BW}$ as oral treatment dose, along with naïve GVT-0 and solvent as controls. The protocols and toxic parameters were all conducted following OECD 423. The study showed that all the treatments on both 300 and $2000 \mathrm{mg} / \mathrm{kg} \mathrm{BW}$ of SNE GVT-0 did not compromise rats' body weight, and toxicity clinical behaviours were observed on the $2000 \mathrm{mg} / \mathrm{kgBW}$ of administration, but there is no significance observed for $300 \mathrm{mg} / \mathrm{kg} \mathrm{BW}$ administration. Microscopic observation under haematoxylin and eosin staining confirmed the clinical findings by showing degeneration and destruction for the most of organs on the $2000 \mathrm{mg} / \mathrm{kg} \mathrm{BW}$ of administration. The results suggest SNE GVT-0 as in category four in OECD 423 globally harmonized classification system (GHS) with estimated LD50 cut-off as $2000 \mathrm{mg} / \mathrm{kg} \mathrm{BW}$.
\end{abstract}

Keywords : Gamavuton-0, self nano-emulsifying system, acute toxicity.

\section{Introduction}

Rheumatoid arthritis (RA) is a chronic inflammation event located in joints, causing degeneration and deformity. Untreated arthritis condition might bring the disease into more advance and persistent inflammation ${ }^{1,2}$. However, available treatments for a chronic inflammatory disease like rheumatoid arthritis nowadays are still hampered by the following side effects such as gastritis and heart attack ${ }^{3}$. Thus, there is a significant demand on safe long term medication for the disease. 
1,5-bis(4'-hydroxy-3'-metoxiphenyl)-1,4-pentadien-3-on, trivially known as Gamavuton-0 (GVT-0), is a modified curcumin compound synthesized from vanillin and acetone via condensation reaction of ClaisenSchmidt ${ }^{4}$. GVT-0 has been proven to have several anti arthritic activities by showing arthritis index reduction in vivo, as well as inhibiting cartilage destruction and suppressing inflammatory cytokines Tumor Necrosis Factor- $\alpha($ TNF- $\alpha$ ) and Interleukin-1 $\beta$ (IL-1 $\beta)$ tissue expressions ${ }^{5}$. However, GVT-0 is still having its mother compound's low water solubility ${ }^{4}$. Rheumatoid arthritis, in one hand, needs a long-term therapy, with GVT-0 possessing low water solubility, in the other hand, is a significant limitation.

Self nano-emulsifying drug delivery system (SNEDDS) has been introduced as a novel approach to effectively overcome compounds problem on water-solubility. The compound is formulated in the oil based system along with surfactant and cosurfactant allowing the auto-formation of nanoemulsion in the gastrointestinal tract without additional external energy. The nano-sized particles would perform an effective GI lumen penetration through both active and passive absorbtion ${ }^{6}$. In a study by Patel et al (2011), SNEDDS system was able to induce in vivo absorption by 7.5 folds $^{7}$. Moreover, the oil based system will escape pHrelated influence of the GI tract thus ideal as a formulation for oral adminitration ${ }^{8}$. In spite of the beneficial effects of the nanocarriers on living cells, undesirable effects may occur. Hence, before marketing a new nanocarrier, extensive toxicity tests are required before it is deemed "safe" for marketing. When sufficient toxicological data from in vitro and in vivo experiments are available, the pharmaceutical then may be applied to a human population. Therefore, data obtained from such tests are then used to extrapolate the doses and effects on humans. Determination of acute toxicity is usually an initial screening step in the assessment and evaluation of the toxic characteristics of newly developed compounds 9

To propose SNEDDS of GVT-0 as a candidate for long-term oral therapy for rheumatoid arthritis, the safety of the system has to be tested. In this study, acute toxicity of SNE GVT-0 has been conducted to see in initial pre-clinical study whether SNE GVT-0 is save in a short period (acute) in the possible dose given in rat.<smiles>COc1cc(/C=C/C(=O)/C=C/c2ccc(O)c(OC)c2)ccc1O</smiles>

Figure 1. Gamavuton-0 chemical structure 1,5-bis(4'-hydroxy-3'-metoxiphenyl)-1,4-pentadien-3-one

\section{Experimental}

\section{Materials}

Gamavuton-0 was provided by Curcumin Research Centre, Faculty of Pharmacy, Universitas GadjahMada, and being engineered into SNE GVT-0 by Biomaterials and Nano-Delivery Research Group, Faculty of Pharmacy, Universitas GadjahMada. The study was performed in the Laboratory Animal Facility, Faculty of Pharmacy, Universitas Gadjah Mada and Laboratory Animal Unit, The Integrated Research and Testing Laboratory, Universitas Gadjah Mada, under ethical approval from Medical and Health Research Committee, Universitas Gadjah Mada. All chemicals and solutions used in the study were analytical standard.

\section{Animals}

Animals used in the study were Rattus norvegicus, male, Sprague-Dawley strain, 200-300 grams, purchased from Biomedics and Basic Technology Centre, Ministry of Health. All animals used in the study were maintained under controlled system, and have been acclimated prior to study.

\section{Methods}

This study is an experimental study performed following the standardized procedure on OECD 423 acute oral toxicity - acute toxic class method. 
Starting dose used in the study of acute toxicity was following standard procedure mentioned in OECD 423. Schematic test procedure with a starting dose of $300 \mathrm{mg} / \mathrm{kg}$ body weight is provided in Figure 2.

Animals were grouped into normal group (aquedest), solvent group, and treatments groups, with three animals per group.

Application volume was not higher than $1 \mathrm{~mL} / 100$ grams body weight. The animals were starved (feed, not drink) overnight before the study, and four hours after application.Toxic effects were intensively observed every 30 minutes in the first 4 hours post-administration. Observation parameters are provided in Table 1.

Oral acute toxicity study was performed by oral administration at the starting dose to the group of three. Whenever death is found after administration on two out of three animals, the study is re-performed at lower dose, but if not, higher dose may be applied. Animal's body weight and mortality were documented daily. Died animal found before 24 hours was then extracted for its vital organs of liver, heart, kidneys, lungs, cerebrum, cerebellum, and spleen, and 10 formalin preserved for histopathology check.

Main study was a 14-day study performed with seven groups of animals as following:

a. Group 1: Treatment group of $300 \mathrm{mg} / \mathrm{kg}$ BW oral administration of SNE GVT-0.

b. Group 2: Normal control group, $1 \mathrm{~mL}$ oral administration of distilled water.

c. Group 3: Solvent control group, oral administration of SNEDDS vehicle equi-volume with the solvent used for $300 \mathrm{mg} / \mathrm{kg}$ BW SNE GVT-0.

d. Group 4: Treatment group of oral administration of $300 \mathrm{mg} . \mathrm{kg}$ BW SNE GVT-0 (replication).

e. Group 5: Treatment group of oral administration of 2000 mg.kg BW SNE GVT-0.

f. Group 6: Treatment group of oral administration of $2000 \mathrm{mg} . \mathrm{kg}$ BW SNE GVT-0 (replication).

g. Group 7: Solvent control group, oral administration of SNEDDS vehicle equi-volume with the solvent used for $2000 \mathrm{mg} / \mathrm{kg} \mathrm{BW} \mathrm{SNE} \mathrm{GVT-0.}$

Observation was conducted for the next 14 days to see the resolution after administration. At the end of day 14 , animals were sacrificed, the vital organs were taken for histopathology analysis.

\section{Histopathology}

Histopathology analysis was performed using haematoxylin and eosin staining.

\section{Data analysis}

Several data were collected and analyzed in the study:

1. Qualitative data of clinical observation on animal's skin, eyes, vital organs function to evaluate local and systemic toxicities, and organs histopathology.

2. Quantitative data of number of animal mortality in each group used for calculating lethal dose 50 cut off (LD50 cut off), and classifying SNE GVT-0 toxicity based on OECD 423.

3. Quantitative data of daily animal weight. The data was statistically analyzed for distribution and the difference significance between groups using one way ANOVA on SPSS 16.0.

\section{Results and Discussion}

\section{Daily changes on body weight}

Averages of animal's body weight daily change is presented in figure 3 , and summarized in table 2 . 


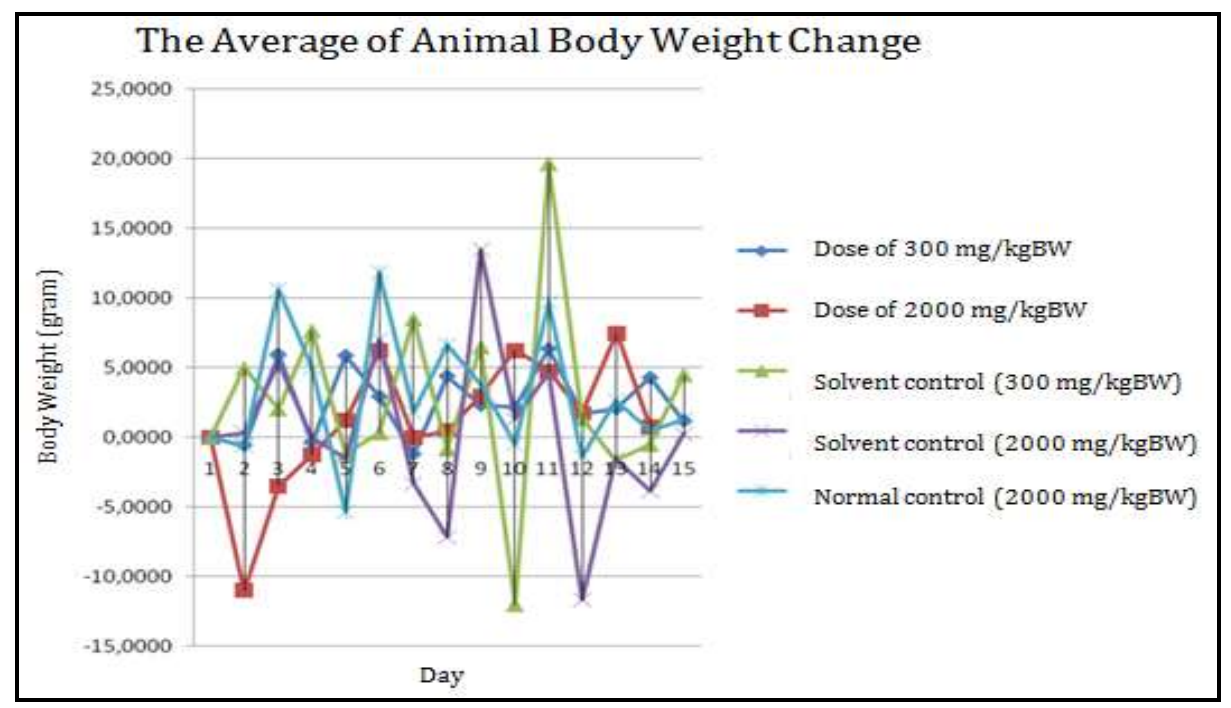

Figure 3. Average daily change of animals' body weight

The study showed that the average of daily body weight change was fluctuated with no significant difference between time points ( $\mathrm{p}>0.05)$. Body weight is a frontier parameter to assess toxicity in general. The result indicates SNE GVT-0 was not giving fatal toxicity as no body weight alteration was shown.

Table 2. Summary of Average daily change of animals body weight

\begin{tabular}{|c|c|}
\hline Test group & The average of weight change \pm S.E.M \\
\hline Dose of $300 \mathrm{mg} / \mathrm{Kg} \mathrm{BW}$ & $2.56 \pm 0.68$ \\
\hline Dose of $2000 \mathrm{mg} / \mathrm{kg} \mathrm{BW}$ & $1.166 \pm 1.26$ \\
\hline Normal control & $3.20 \pm 1.34$ \\
\hline Solvent control $(300 \mathrm{mg} / \mathrm{kg} \mathrm{BW})$ & $2.49 \pm 1.89$ \\
\hline Solvent control $(2000 \mathrm{mg} / \mathrm{kg} \mathrm{BW})$ & $0.26 \pm 1.66$ \\
\hline
\end{tabular}

\section{Clinical observation}

SNE GVT-0 administration of $2000 \mathrm{mg} / \mathrm{kgBW}$ was performed after no mortality was found on 300 $\mathrm{mg} / \mathrm{kg} \mathrm{BW}$. On $2000 \mathrm{mg} / \mathrm{kg} \mathrm{BW}, 100$ per cent mortality was found on group 5. On group 6, toxicity was observed as diarrhea, change on behaviors, and passivity. The toxicity was also observed on group 7 , where equi-volume solvent of $2000 \mathrm{mg} / \mathrm{kg} \mathrm{BW}$ was administered. Although the administration was done in 3 phases with 2 hours gap per phase, toxicity seems to be unavoidable.

Animals' organ weight is featured in table 3. Kruskal-Wallis statistical analysis showed no significance on organ weight between animals $(\mathrm{p}=0.05)$. Significant change in organ weight might indicate severe toxicity, which was not the case for SNE GVT-0.

Table 3. Animal organs weight

\begin{tabular}{|c|c|c|c|c|c|c|c|c|}
\hline Test group & Cerebrum & Cerebellum & Liver & Heart & Kidney & Spleen & Lungs & Stomach \\
\hline Dose of $300 \mathrm{mg} / \mathrm{kg} \mathrm{BW}$ & $1.38 \pm 0.088$ & $0.56 \pm 0.065$ & $9.20 \pm 0.774$ & $0.81 \pm 0.035$ & $1.63 \pm 0.131$ & $0.63 \pm 0.069$ & $1.85 \pm 0.268$ & $1.51 \pm 0.168$ \\
\hline Dose of $2000 \mathrm{mg} / \mathrm{kg} \mathrm{BW}$ & $1.19 \pm 0.020$ & $0.31 \pm 0.022$ & $5.88 \pm 0.269$ & $1.04 \pm 0.125$ & $1.38 \pm 0.062$ & $0.28 \pm 0.028$ & $1.60 \pm 0.213$ & $1.31 \pm 0.301$ \\
\hline Normal control & $1.41 \pm 0.023$ & $0.59 \pm 0.057$ & $8.50 \pm 0.306$ & $0.85 \pm 0.034$ & $1.69 \pm 0.025$ & $0.60 \pm 0.019$ & $1.61 \pm 0.066$ & $1.53 \pm 0.145$ \\
\hline Solvent control $(300 \mathrm{mg} / \mathrm{kg}$ BW & $1.46 \pm 0.026$ & $0.56 \pm 0.009$ & $8.63 \pm 0.279$ & $0.80 \pm 0.030$ & $1.64 \pm 0.120$ & $0.58 \pm 0.013$ & $1.55 \pm 0.103$ & $1.56 \pm 0.098$ \\
\hline Solvent control (2000 mg/kg BW) & $1.41 \pm 0.004$ & $0.44 \pm 0.073$ & $5.93 \pm 0.415$ & $0.709 \pm 0.077$ & $1.29 \pm 0.125$ & $0.46 \pm 0.053$ & $1.43 \pm 0.124$ & $1.58 \pm 0.107$ \\
\hline
\end{tabular}




\section{Histopathology}

Histopathology of the organs is summarized in table 4.Most clinical abnormalities were observed in the lymph and lungs for all the dose given to the animals. Minor bleeding was found in the lymph, probably due to solvent toxicity since the output appeared in the solvent control group. The toxicity shown in the lungs was due to the high air concentration of ammonia, because oral administration of the drug would not give directly affect the lungs by all possible pathways. In the higher dose with higher volume of oral administration, autolysis were found also in the kidney. This appearance was probably due to solvent toxicity since the pathology was also observed in the solvent control group in both lower and higher volume of administration. In general, in the histopathological observation on SNE GVT-0, no fatal drug-related damage was found in the study.

Table 4. Histopathology observation result of the organs of all treated animal groups

\begin{tabular}{|c|c|c|c|c|c|c|c|c|}
\hline \multicolumn{9}{|c|}{ Group I (300mg/kg BW replication) } \\
\hline \multirow{2}{*}{ Animal test } & \multicolumn{8}{|c|}{ Organ } \\
\hline & Stomach & Kidney & Liver & Spleen & Lungs & Heart & Cerebrum & Cerebellum \\
\hline 1 & NPC & NPC & $\mathrm{HD}$ & HMS, DRP & $\mathrm{PI}, \mathrm{H}, \mathrm{PV}$ & NPC & NPC & NPC \\
\hline 2 & NPC & NPC & NPC & HMS, DRP & $\mathrm{PI}, \mathrm{PV}$ & NPC & NPC & NPC \\
\hline 3 & NPC & NPC & NPC & HMS & GP, BLS & NPC & NPC & NPC \\
\hline \multicolumn{9}{|c|}{ Group II (aquades control) } \\
\hline \multirow{2}{*}{ Animal test } & \multirow{2}{*}{\multicolumn{8}{|c|}{ Organ }} \\
\hline & & & & & & & & Cerebellum \\
\hline 1 & NPC & NPC & NPC & NPC & $\mathbb{I P}$ & NPC & NPC & NPC \\
\hline 2 & NPC & NPC & NPC & NPC & IP, PV & NPC & NPC & NPC \\
\hline 3 & NPC & NPC & NPC & NPC & IP & NPC & NPC & NPC \\
\hline \multicolumn{9}{|c|}{ Group III (solven control group; $300 \mathrm{mg} / \mathrm{kg} \mathrm{BW}$ ) } \\
\hline \multirow{2}{*}{ Animal test } & \multirow{2}{*}{\multicolumn{8}{|c|}{$\begin{array}{c}\text { Organ } \\
\text { Spleen }\end{array}$}} \\
\hline & & Kidney & Liver & Spleen & Lungs & Heart & Cerebrum & Cerebellum \\
\hline 1 & NPC & \multirow{3}{*}{$\begin{array}{c}\text { HTED, NPC } \\
\text { HTED, } \\
\text { METN } \\
\text { NPC }\end{array}$} & $\mathrm{FD}, \mathrm{HD}$ & HMS & $\mathrm{IP}, \mathrm{PV}$ & NPC & NPC & NPC \\
\hline 2 & NPC & & NPC & DRP & IP, PV & NPC & NPC & NPC \\
\hline 3 & NPC & & $\mathrm{FD}$ & HMS & IP & NPC & NPC & NPC \\
\hline \multicolumn{9}{|c|}{ Group IV (300 mg/kg BW) } \\
\hline \multirow{2}{*}{ Animal test } & \multicolumn{8}{|c|}{ Organ } \\
\hline & Stomach & Kidney & Liver & Spleen & Lungs & Heart & Cerebrum & Cerebellum \\
\hline 1 & NPC & METN, NPC & NPC & HMS & $\mathrm{IP}, \mathrm{H}, \mathrm{PV}$ & NPC & NPC & NPC \\
\hline 2 & NPC & NPC & NPC & HMS, DRP & $\mathrm{IP}, \mathrm{PV}$ & NPC & NPC & NPC \\
\hline 3 & NPC & NPC & NPC & NPC & IP & NPC & NPC & NPC \\
\hline \multicolumn{9}{|c|}{ Group V (2000 mg/kg BW) } \\
\hline \multirow{2}{*}{ Animal test } & \multicolumn{8}{|c|}{ Organ } \\
\hline & Stomach & Kidney & Liver & Spleen & Lungs & Heart & Cerebrum & Cerebellum \\
\hline 1 & Autolysis & Autolysis & Autolysis & $\mathrm{DMCL}+$ & Autolysis & NPC+ + & NPC & NPC \\
\hline 2 & Autolysis & Autolysis & Autolysis & NPC & Autolysis & $\mathrm{NPC}+$ & Autolysis & Autolysis \\
\hline 3 & Autolysis & Autolysis & NPC & DRP & IP & NPC+ & Autolysis & Autolysis \\
\hline
\end{tabular}

\begin{tabular}{|c|c|c|c|c|c|c|c|c|}
\hline \multicolumn{9}{|c|}{ Group VI (2000 mg/kg BW replication) } \\
\hline \multirow{2}{*}{ Animal test } & \multicolumn{8}{|c|}{ Organ } \\
\hline & Stomach & Kidney & Liver & Spleen & Lungs & Heart & Cerebrum & Cerebellum \\
\hline 1 & NPC & NPC & NPC & DRP & $\mathrm{IP}, \mathrm{PV}$ & NPC & NPC & NPC \\
\hline 2 & NPC & NPC & NPC & DRP & IP, PV & NPC & NPC & NPC \\
\hline 3 & Autolysis & Autolysis & Autolysis & Autolysis & Autolysis & NPC & NPC & NPC \\
\hline \multicolumn{9}{|c|}{ Group VII (solvent control; 2000 mg/kg BW) } \\
\hline \multirow{2}{*}{ Animal test } & \multicolumn{8}{|c|}{ Organ } \\
\hline & Stomach & Kidney & Liver & Spleen & Lungs & Heart & Cerebrum & Cerebellum \\
\hline 1 & $G$ & NPC & NPC & HMS, DRP & IP,PV & NPC & Autolysis & Autolysis \\
\hline $\begin{array}{l}2 \\
3\end{array}$ & $\underset{G}{\mathrm{NPC}}$ & $\begin{array}{l}\text { NPC } \\
\text { NPC }\end{array}$ & $\begin{array}{l}\text { NPC } \\
\text { NPC }\end{array}$ & HMS, DRP & $\begin{array}{l}\text { IP, PV } \\
\text { IP, PV }\end{array}$ & NPC & NPC & $\begin{array}{l}\text { NPC } \\
\text { NPC }\end{array}$ \\
\hline & & & & & & & & \\
\hline
\end{tabular}

1. NPC: No pathological changes

2. HD: Hydropic Degeneration, characterized by the size of enlarged hepatocytes with discolored cytoplasmic vacuoles.

3. FD: Fatty Degeneration, characterized by vacuoles of various sizes with clear boundaries in the cytoplasm. Partial core hepatocytes pushed to the edge.

4. IP: Intertitialis Pneumonia, characterized by infiltration of lymphocytes and macrophages in the alveoli intestitial network, so that the interstitial tissue was thickened.

5. G: Gastritis, characterized by mucosal epithelial erosions accompanied with infiltration of eosinophils, neutrophils, and lymphocytes in the tunica mucosa and submucosa. 
6. HTED: Hidropil Tubular Epithelial Degeneration, characterized by tubular epithelial cell size is bigger, and the color becomes faint cytoplasm with vacuoles in it.

7. GP: Granulomatous Pneumonia, pneumonia characterized by granulamatosa. Granulomatous inflammation, it appears the central caseating necrosis and infiltration of neutrophils and limfost and Giant cells and encapsulated or surrounded by connective tissue.

8. METN : Most Epithelial Tubules Necrosis, characterized by partly renal tubular epithelial cell nucleus become piknotik.

9. BLS: bronkhiolitis supuratifa, characterized by destruction of bronchial epithelial cells and inflammatory cells in the bronchial lumen accompanied with neutrofil infiltration, lymphocytes, and macrophages in bronkhiolus.

10. H: Hemorrhage/Bleeding, characterized by erythrocytes outside organ of the circulatory system.

11. PV: Pevivalkulitis, inflammation around blood vessels, characterized by neutrophil and lymphocyte infiltration around blood vessels.

12. HMS: Hemosiderin, hemosiderin pigment in red pulp in considerable amounts.

13. DRP: Depletion of Red Pulp, characterized by few erythrocytes and charged by the network backers (trabecular) and blood vessels.

14. Autolysis: Autolysis postmortem, the damage to the cell / tissue / organ that occurs after the animal died because of proteolytic enzymatic reactions or spoilage bacteria. Characterized by cell death characterized by kariopiknotik uniform as well as many core extrudate (out of cell).

\section{Conclusion}

Due to the limited solubility capacity of the compound in CMC-Na system, toxicity testing had to be done in a high volume of suspension. In the higher dose, the volume became extremely higher and might have more significant influence of the toxicity as a whole product. In the lower dose of SNE GVT-0 with lower application volume, there is no observed acute pre-clinical toxicity of SNE GVT-0.

\section{Acknowledgements}

We would like to acknowledge Curcumin Research Centre, Faculty of Pharmacy, Gadjah Mada University, Yogyakarta for providing GVT-0 in this study. We also would like to address a gratitude to Hibah Kompetensi and Penelitian Disertasi Doktor Kemenristekdikti and Nanopharmacy Research Center UII for the funding to conduct a significant part of the study.

\section{References}

1. I.B. McInnes and G. Schett, N. Engl. J. Med., 365, 2205 (2011); doi:10.1056/NEJMra1004965.

2. F.A. Cooles and J.D. Isaacs, Curr. Opin. Rheumatol., 23, 233 (2011); doi:10.1097/BOR.0b013e32834518a3.

3. J.N. Clements, Formulary, 46, 532 (2011).

4. Sardjiman. Synthesis of some new series of curcumin analogues, antioxidative, anti-inflammatory, antibacterial activity, and qualitative structure-activity relationship, dissertation, Gadjah Mada University, Yogyakarta. 2000.

5. Z. Ikawati, N. Yuniarti and S.A. Margono, J. Appl. Pharm. Sci., 4, 19 (2014).

6. A.A. Date, N. Desai, R. Dixit and M. Nagarsenker, Nanomedicine (Lond.), 5, 1595 (2010); doi:10.2217/nnm.10.126.

7. J. Patel, A. Patel, M. Raval and N. Sheth, J. Adv. Pharm. Technol. Res., 2, 9 (2011); doi:10.4103/22314040.79799.

8. I. Cherniakov, A.J. Domb and A. Hoffman, Expert Opin. Drug Deliv., 12, 1121 (2015); doi:10.1517/17425247.2015.999038.

9. Z. Tubesha, M.U. Imam, R. Mahmud and M. Ismail, Molecules, 18, 7460 (2013); doi:10.3390/molecules 18077460 . 